\section{Inner visions}

\section{The Ovary of Eve: Eggs and Sperm and Preformation}

by Clara Pinto-Correia

University of Chicago Press: 1997.

Pp. 376. $\$ 29.95$

\section{Frank Gonzalez-Crussi}

How do we come into being? Few questions are as fundamental, or as appealing to the imagination, as this one. The process by which we are shaped into existence is a phenomenon at once commonplace and portentous. Millions are conceived and millions born every day, following an unvarying plan. Yet who could fail to be filled with wonder when confronted by the spectacle of an inchoate, tiny germ that develops symmetry, forms eyes, sprouts limbs and ultimately becomes a fully formed individual?

Considering the inexhaustible suggestiveness of this process, and the amount of folly, passion, fantasy, wild speculation and serious investigative effort that it has given rise to, it is surprising that relatively few readable historical accounts have been written. True, histories of embryology have been compiled before, but most fail to do justice to the multi-hued tints and ramifications that their subject matter offers at every juncture. This deficiency is amply corrected by Clara Pinto-Correia.

Her engrossing book is likely to remain for many years the most readable and informative - certainly the most enjoyable account of the early scientific efforts to explain human conception. This is not surprising. As a professor of developmental biology, the author has the necessary background to assess the relative importance of the various contributions; as an established novelist and poet, she brings to the task clear, agile prose, and a gifted eye for vivid, evocative and memorable material.

When old ideas and hypotheses, no matter how exalted, are superseded by new evidence, they must be cast aside. This attitude is inherent in the much-revered scientific method, and is no doubt commendable in the scientist. The historian, however, ought to prize the obsolete. Yet, when describing discarded hypotheses, historians often sound steeped in the conviction that they are merely chronicling past errors. Their tone tends to turn contemptuous, and the reader senses their amazement at the credulity of our forebears, by whom the absurd, far-fetched notions were sustained.

It is a strength of The Ovary of Eve that it succeeds in fully appropriating the viewpoint of the scientists of the past, and makes the reader realize the nobility, the earnestness, the inevitability and the beauty of many of their constructs, even those condescend-
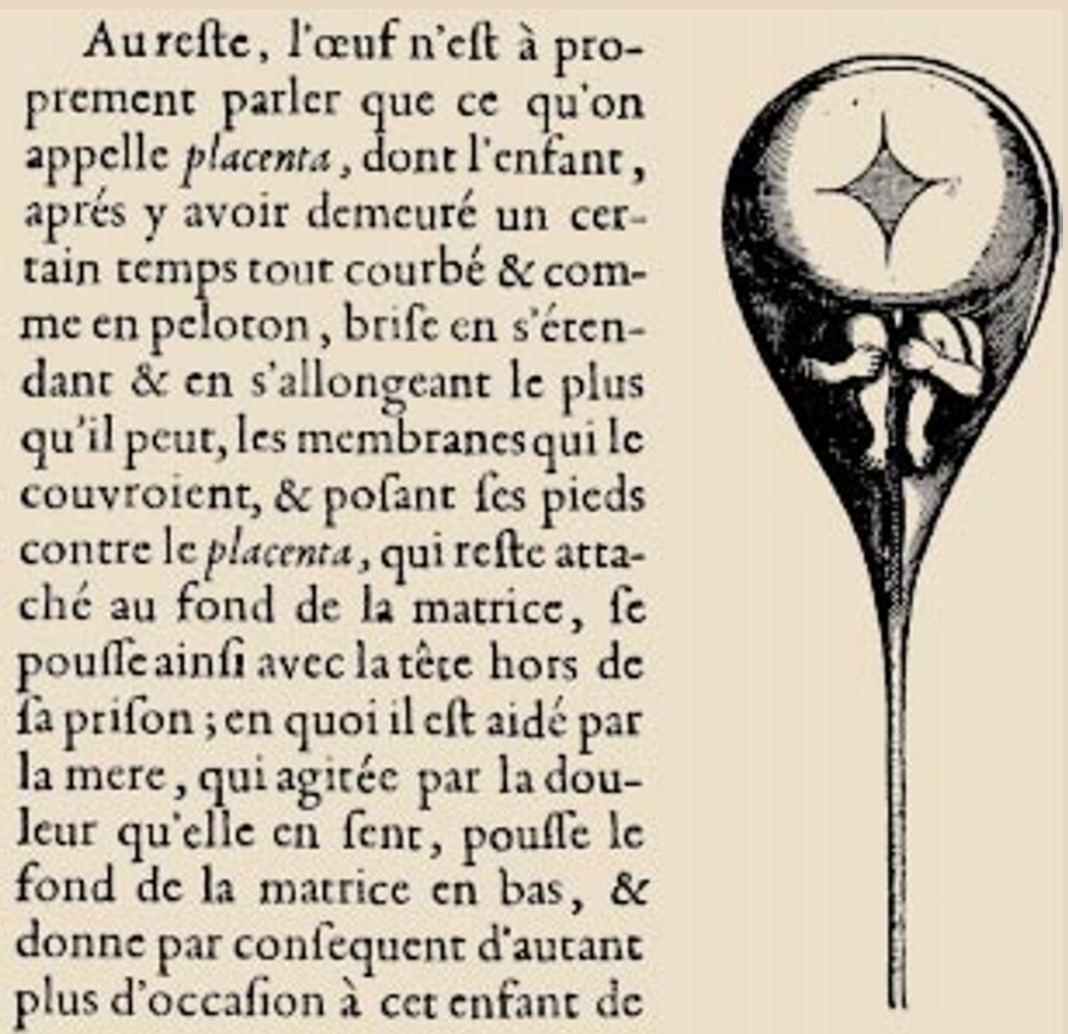

Human fetus in a sperm from Nicolas Hartsoeker's Essay de Dioptrique (1694), which is largely a treatise on optics and optical instruments. His extreme preformation theory proposed that "the first males would have been created with all those... that would be born until the end of the centuries".

ingly dismissed as 'foolishness' by less perceptive historians. "It is a sad fact," the author tells us in the prologue, "that history is written by the victors. In this book, I want to challenge this trend, and tell the marvellous story of the losers."

'Marvellous' is right, and rendered more so by the lively style of the narrative. But, as the book comes to an end, it is by no means clear that there are winners and losers. The reader is made to realize that the confrontation between preformationism and epigenesis is far from over; that the fundamental concepts remain the same, even though the warring factions take on a different guise each time; and that we are not quite through with mulling the notion, first propounded early in the present century, that ontogenesis is "a cytoplasmic epigenesis, underlain by a nuclear preformationism”.

Or, as Stephen Jay Gould asserts in the foreword, our present view of morphogenesis is epigenetic but, to the extent that we acknowledge a pre-existing 'blueprint' that directs all activities, preformationism may still be said to be alive and well and domiciled in the nucleus.

The subtitle, Eggs and Sperm and Preformation, is inaccurate. The book is much broader in scope and richer than that. We see Lazzaro Spallanzani fitting frogs with boxer shorts to ascertain the role of semen in fecundation (but to the end believing that sperm cells were mere contaminants). We find the microscopists - Leeuwenhoek, Hartsoeker and $\mathrm{Du}$ Bois-Regard - expounding their ideas and flinging sarcasm at each other. And whereas Ambroise Paré and Ulisse Aldrovandi explain the causation of monstrous births, Vandermonde, eugenist avant la lettre, enlightens us on the ways to perfect the human species.

But there is much more. Reference to Hartsoeker's 'homunculus' leads to considerations on the Egyptian goddess $\mathrm{Ka}$, the work of the Arab alchemist Jâbir Ibn Hâyan, the Jewish myth of the Golem, Francesco Redi's experiments on generation, the fairy tales of François de la Plantade and so on. Interesting and erudite connections abound in each of the eight engrossing chapters.

The book is an individual and idiosyncratic work. That may be one of the reasons why it accomplishes so well the ends that Vandermonde, according to the prologue, wished for his own production: "To first detain the reader before novel and amusing objects, that in treading the path of beauty he may arrive effortlessly to that of science." Frank Gonzalez-Crussi is in the Department of Pathology, Children's Memorial Hospital, Chicago, Illinois 60614, USA. 